\title{
Transient Global Amnesia
}

National Cancer Institute

\section{Source}

National Cancer Institute. Transient Global Amnesia. NCI Thesaurus. Code C85198.

A condition characterized by sudden, temporary, usually short-lived memory loss, not associated with a neurologic disorder. Affected individuals lose memory function for recent events and have a decreased ability to retain new information. It is usually a solitary event. 